\title{
The Impacts of Service Related Exposures on Trajectories of Mental Health Among Aging Veterans
}

\author{
Stephanie Ureña ${ }^{1}$, Miles G. Taylor ${ }^{2}$, and Ben Lennox Kail ${ }^{3,4}$
}

'Department of Sociology, Florida State University, Tallahassee. ${ }^{2}$ Pepper Institute for Aging and Public Policy, Florida State University, Tallahassee. ${ }^{3}$ Department of Sociology, Georgia State University, Atlanta. ${ }^{4}$ The Gerontology Institute, Georgia State University, Atlanta.

Correspondence should be addressed to Stephanie Ureña, Department of Sociology, Florida State University, 526 Bellamy Building, 113 Collegiate Loop, Tallahassee, FL 32306. E-mail: su06c@my.fsu.edu

Received February 22, 2016; Editorial Decision Date November 1, 2016

Decision Editor: Deborah Carr, PhD

\begin{abstract}
Objectives: Drawing on life-course perspective and cumulative advantage theory, we examined whether service related exposures (SREs)—combat and exposure to death—have lasting impacts on depressive symptom and psychiatric problem trajectories of aging veterans.

Methods: The Health and Retirement Study and linked 2013 Veterans Mail Survey were used to examine SREs and mental health among older veterans between 2002 and $2012(N=1,662)$. Latent growth curves were used to measure how individuals vary from average mental health trajectories based on SREs and other important covariates.

Results: Exposure to death had a significant and lasting effect on depressive symptoms for veterans in late life but was reduced to nonsignificance when physical health trajectories were included. Combat and exposure to death had independent and robust impacts on psychiatric problems, which were robust in final models.

Discussion: SREs presented varied and significant impacts, suggesting that combat does not work alone in driving poor mental health trajectories, and that exposure to death is a more robust risk marker for later outcomes.
\end{abstract}

Keywords: combat—exposure to death—latent growth curves—military

Approximately 22 million veterans live in the United States (U.S. Census Bureau, 2010) and $41 \%$ of those veterans are 65 and older. Approximately 3 million veterans over the age of 65 receive care from the VA health care system (Veterans Health Administration [VHA], 2015) and many need mental health services (Sorrell \& Durham, 2011). One of the many reasons for seeking mental health services is because depression diagnoses and treatment increase after age 65 (Zivin, Pirraglia, McCammon, Langa, \& Vijan, 2013).

Roughly $11 \%$ of older veterans have a major depressive disorder diagnosis, which is double the rate of the general population (VHA, 2015). Older adults with depressive symptoms make more medical visits, use more medication, incur higher outpatient charges, and stay in the hospital longer (CDC, 2008). The most serious consequence of depression, and mental illness in general, is suicide (VHA, 2015). Although young veterans are at the highest risk, veterans over the age of 65 are at an increased risk for suicide compared with middle-aged veterans (VHA, 2015).

The present literature has not established the circumstances fueling poor mental health as veterans age. Combat and other service related exposures (SREs) are circumstances that may have long reaching mental health impacts, and reduced mental health at older ages may also be due to poorer physical health and factors such as marital disruption (Burland \& Lundquist, 2013). Regardless, poor mental health among older veterans is not considered part of the normal aging process and remains a national public health concern (CDC, 2008; VHA, 2015). 
Contributing to this concern, the majority of older veterans served during wartime (Wilmoth \& London, 2013). Wartime service is varied and may involve deployment and trauma which can disrupt the life course and manifest into mental health problems (George, 2007; Wilmoth, London, \& Parker, 2010). Increased mental health risk for WWII and Korean War veterans in Europe may be observed decades after service (Hunt \& Robbins, 2001), but less is known about more recent cohorts of U.S. veterans (Settersten, 2006). In addition, little is known about specific SREs that pose latent or lasting effects for mental health in older veterans.

Despite their importance to mental health, SREs are usually not examined directly in longitudinal, population based surveys where connections to health and wellbeing can be established (Taylor, Ureña, \& Kail, 2016). Most studies on older veterans use a simple marker of veteran status, or historical period of war, in linking service to later outcomes. Although informative, these variables are a proxy for numerous experiences related to military service that are potentially harmful-exposure to combat-and helpful-G.I. Bill (Elder, Shanahan, \& Clipp, 1994, 1997; Sampson \& Laub, 1996; Settersten, 2006). Therefore, it is not clear which experiences are most salient in predicting mental health for older veterans. While SREs are studied in the short term among 24-33 yearold All Volunteer Force (AVF) veterans (Cesur, Sabia, \& Tekin, 2013); longitudinally for physical health outcomes among older conscript-era veterans (Taylor et al., 2016); and longitudinally for health outcomes of repatriated prisoners of war (Kaiser et al., 2011; King et al., 2015; Park, Kaiser, Spiro, King, \& King, 2012), they have yet to be examined using longitudinal, population representative data with respect to mental health outcomes in later life (MacLean, 2013).

Our study addresses this gap in the literature by examining SREs available in the 2013 Veterans Mail Survey (VMS) linked to the Health and Retirement Study (HRS). The dynamic nature of SREs and the evidence of differential timing of effects (e.g., immediate or delayed risk) for mental health make this line of research critical for understanding the complex lifetime risk associated with service and especially wartime experiences. Drawing on the life-course perspective (Elder, 1994) and cumulative disadvantage theory (O'Rand, 1996), we examine nondiagnosed depressive symptoms using the shortened 8-item CESD scale and dichotomous doctor diagnosed psychiatric problem trajectories over a decade in order to estimate the independent and lasting effects of SREs on the mental health of today's older veterans.

\section{Theoretical Framework}

The life-course perspective addresses how historical time and place shape lives, and its empirical literature uses age-graded trajectories to understand individual variation and patterns in the long-term consequences of life events (Elder, 1994; George, 2003). The military is an important social institution whose context can alter the course of social and health trajectories. Military service during specific historical periods by individuals with specific characteristics may (re)structure the processes of cumulative advantage/disadvantage that lead to later-life disparities in health outcomes (Wilmoth \& London, 2013), making it ideal for studying through the life-course lens. The positive and/or negative effects of military service can be (a) lifelong, (b) multidimensional, and (c) experienced within an environment of social relationships that can protect or exacerbate risk (Spiro, Settersten, \& Aldwin, 2016).

Within the life-course framework, cumulative advantage/disadvantage (CAD) theory addresses how early factors and experiences unfold and impact later outcomes (O’Rand, 1996). Military service experiences are variable within and across cohorts and have the potential for positive, null, or negative outcomes. These effects may be short-term, but may also accumulate to create growing advantage or disadvantage in later life (Spiro et al., 2016). Importantly, cumulative processes often involve chains of risk or reward, such that early life experiences set individuals on distinct economic or social paths. In this way, the effects of early experiences may have both direct and indirect influences on later life outcomes (Ferraro \& Shippee, 2009). Unfortunately, SREs are largely invisible risk factors in the life-course literature, though the percentage of older veterans is substantial (Settersten, 2006; Spiro et al., 2016). Our study is unique in that the primary experiences thought to place veterans at increased risk of poor mental health are directly measured to address whether and how these exposures link military service to mental health across the life course.

\section{Background}

Wartime service poses a threat to the mental health of veterans (Davies, 2001; Elder, Clipp, Brown, Martin, \& Friedman, 2009; Schnurr, Spiro, \& Paris, 2000), and the negative effects often increase as veterans age (Settersten, 2006). Although the impact of wartime service is established, there is considerable variation among veterans regarding SREs, especially because a large portion of wartime veterans never experienced combat. All wartime veterans experience disruption and uncertainty, but military service on the home front does not produce the same disruption or potential trauma as direct exposure to combat (Elder et al., 2009). Therefore, it is difficult to distinguish whether it is any wartime service or specific SREs that matter most for the long-term mental health of veterans (Wilmoth et al., 2010).

Although retrospective research on older veterans often fails to capture SREs, there is evidence of variation in combat experiences relevant for understanding later outcomes. 
Elder, Pavalko, and Clipp (1992) used archival data of 343 WWII veterans to determine variations in combat experience: $26 \%$ heavy combat, $18 \%$ light combat, and $56 \%$ no combat. Heavy combat was most salient for later outcomes. Severity of trauma exposure during combat accounts for different rates of mental health problems (Gold et al., 2000). Those who experience the most extreme form of military trauma, prisoner of war, are especially susceptible to issues like depression and psychiatric problems (Gold et al., 2000). Although levels of combat exposure are not mutually exclusive, heavy combat may include exposure to death which may particularly produce cognitive or emotional stressors such as survivor's guilt, fear, helplessness, or moral injury (Maguen \& Litz, 2012; Spiro, Schnurr, \&, Aldwin, 1994).

Moral injury stemming from warfare is an emerging concept in the veteran mental health literature (Maguen $\&$ Litz, 2012). A moral injury results when someone commits or witnesses an act that does not match their moral standards, thus leading to negative mental health outcomes expressed through feelings of shame or guilt (Litz et al., 2009; Maguen \& Litz, 2012). Although it does not require a diagnosis, moral injury is correlated to PTSD and other stress-related mental health symptoms, and its dynamic nature makes the effects intermittent, often manifesting in later life instead of immediately following a traumatic event (Litz et al., 2009; Maguen \& Litz, 2012). Such latent combat-related psychiatric symptoms can occur in previously asymptomatic veterans up to 50 years later (Spiro et al., 1994), a phenomenon called later-adulthood trauma reengagement (LATR). LATR is a process of reengaging with trauma memories, which may be resolved successfully and lead toward meaning-making, posttraumatic growth, wisdom, or not be successfully resolved and lead toward rumination, depression, or lateonset PTSD (Davison et al., 2016). Those who experience psychological injury from combat are also at higher risk for physical and psychiatric disability and impairment decades later (Elder, Shanahan, \& Clipp, 1997; Spiro et al., 2016).

In addition to lasting direct effects, SRE's may pose indirect threats to mental health through relationship and social stressors. For example, marriage and marital disruption are important for life-course mental health outcomes (Barrett, 2000). A longitudinal study finds that veteran status is strongly associated with divorce compared with nonveterans, due in part to factors such as life-course disruption and combat exposure (London, Allen, \& Wilmoth, 2013; Pavalko \& Elder, 1990). Further, combat exposure is significantly associated with antisocial behavior and stress, which is linked to marital adversity (Gimbel \& Booth, 1994). Consequently, it is possible that marital disruption may be one pathway through which wartime SREs indirectly impact the long term mental health of veterans.

Also linked to mental health at later ages is physical health (Taylor \& Lynch, 2004). There are long-term physical health implications for aging veterans, particularly among those exposed to hazardous or traumatic conditions (Taylor et al., 2016; Wilmoth et al.,2010). These connections are observed in clinical settings, where depressed veterans are likely to exhibit physical and mental health comorbidities (Karlin et al., 2015). These findings suggest that physical health may be another important life-course pathway through which SREs indirectly impact the long-term mental health of veterans.

In the context of the current literature, this study is unique because it extends the examination of SREs to mental health trajectories of older veterans in a nationally representative longitudinal survey. Further, it addresses two specific SREs thought to be particularly salient for mental health: exposure to combat and exposure to the dead, dying, and wounded (death). The heterogeneity within military service experiences are increasingly important to understanding the variation in health trajectories and outcomes in later life, and the present study aims to assess the following hypotheses:

Hypothesis 1 (H1): Consistent with findings on the negative mental health consequences of wartime service, older veterans are likely to experience increasing amounts of depressive symptoms and new or continued psychiatric problems as they age.

Hypothesis $2(\mathrm{H} 2)$ : Consistent with life-course disruption and cumulative disadvantage theory, veterans who self-report combat and exposure to death are at increased risk for more depressive symptoms and new or continued psychiatric problems than veterans who did not experience SREs. Additionally, exposure to death will be more detrimental to depressive symptoms and psychiatric problems than exposure to combat.

Hypothesis 3 (H3): Physical health and marital disruption life-course pathways will account for some of the effects of SREs on depressive symptoms and psychiatric problems.

Our study used structural equation modeling (SEM) based latent growth curves (LGC) among an HRS sample of veterans to achieve two analytic goals. First, we examined 10-year trajectories of depressive symptoms and psychiatric problems among veterans in later life. Second, we examined the impact of combat and exposure to death on later life mental health trajectories along with salient confounders and life-course pathways. These findings provide valuable insight into variation in later life mental health trajectories of today's older veterans.

\section{Methods}

\section{Data}

The 2013 VMS along with linked files from the RAND HRS Data File (v.N) were used for analyses. The HRS sampled 12,652 people born between 1931 and 1941 and their spouses, including an oversample of African Americans. Biennial follow-ups resulted in a 16-year panel study designed to explore the health and economic circumstances of aging Americans (HRS, 2008; NIA, 2007). 
The 2013 VMS is a data supplement focused on veteran military experiences mailed to a subsample of 3,811 HRS respondents who answered "Yes" to the question "Have you ever served in the active military?" in any wave of the HRS study. The survey resulted in a $49 \%$ response rate for a total subsample of 1,874 HRS veterans. We linked these records to the RAND HRS Data file (v.N), keeping only respondents that merged across datasets for an analytic sample of 1,860 veterans. The RAND HRS file was used to access trajectories of mental health between 2002 and 2012 along with other health-related and demographic variables for the participants of the 2013 VMS. Comparison of the VMS sample to the core HRS veterans suggests they are slightly younger and more advantaged (Taylor et al., 2016). The analytic sample of VMS participants $(N=1,860)$ was further limited by excluding individuals with missing data on both outcome variables at the trajectory intercept in $2012(N=93,5.00 \%)$, and individuals with missing data on explanatory variables $(N=116,6.24 \%)$. This resulted in a final analytic sample size of 1,662 for a 10 -year analytic period (2002-2012) with time points over Waves 6-11 of the HRS. Missing cases in the outcome variables over time were handled with a full information maximum likelihood estimator, which rests on the assumption that items are missing at random.

\section{Outcome Measures}

We examined the association of SREs with mental health trajectories using two separate outcome measures capturing nondiagnosed and diagnosed mental health risk: selfreported depressive symptoms and diagnosed psychiatric problems taken from the HRS file between 2002 and 2012. Depressive symptoms were measured as a single summed index of depressive symptoms from the established Center for Epidemiologic Studies Depression Scale (CESD) (Radloff, 1977). The HRS uses a revised 8-item version of the 20-item CESD index, with detailed analysis supporting its quality (Steffick, 2000). The 8-item CESD scale includes negative indicators: depression, everything is an effort, sleep is restless, felt alone, felt sad, could not get going, along with reverse coded positive indicators: felt happy and enjoyed life. Psychiatric problems were measured as wave specific dichotomous questions between 2002 and 2012 regarding whether or not a doctor told the respondent if he or she currently had emotional, nervous, or psychiatric problems (no psychiatric problem $=0$ ). We used the wave specific self-report of psychiatric problems because it enabled us to capture persistent and new diagnoses throughout the study's 10-year period (2002-2012).

\section{Explanatory Measures}

The two main predictors of interest are SREs during active military service, taken from the VMS. Exposure to combat was measured by a single question asking whether the respondent ever served in a combat or war zone (not exposed $=0$ ). Exposure to death was measured with the question: During your military service, were you ever exposed to dead, dying, or wounded people? (not exposed $=0$ ). Exposure to combat and exposure to death are two separate variables in our analyses, and although they are not mutually exclusive, they both describe the distinguishing experiences of a single veteran during their service tenure. Sociodemographic controls included gen$\operatorname{der}($ male $=1$, female $=0)$, race $($ White $=1$, other $=0)$, educational attainment in years, self-reported duration of military service in years (to handle the impact of longer/ repeated exposures or deployments), and period of service variables. The period of service variables were created from service start and end dates self-reported in the 2013 VMS. Since we include a duration of service variable in the analyses and had a very small veteran sample serving in multiple wars, we coded period of service as the first war period veterans served in. World War II was defined as 1941-1946, Korean War as 1950-1955, and Vietnam War as 1964-1975, which are the years used by the VA to determine eligibility for wartime service benefits (U.S. Code of Federal Regulations, 2016; Wilmoth, London, \& Parker, 2010). The period of service variables in the analysis are WWII (yes $=1$ ), Korea (yes $=1$ ), Vietnam (yes $=1$ ), with none as the reference group.

Two life-course pathways were also included to understand the indirect impacts of SREs on later life mental health: marital disruption and physical health. The measures of ever divorced (yes = 1) and ever widowed (yes = 1) captured marital disruption. Divorced or widowed status was constructed using wave specific current marital status variables between 2002 and 2012. These variables captured previous divorce or widowhood as long as the respondent was not remarried at time of study entry (2002).

We also examined physical health to understand the links between SREs and mental health among veterans. Two physical health variables were included: functional limitations (FLs) and number of chronic conditions. FLs were measured as a summed 6-item index including self-reports of difficulty with any of the following activities: walking one block; climbing one flight of stairs; lifting or carrying 10 pounds; picking a dime up off the ground; stooping, kneeling, or crouching; and pushing or pulling large objects. We created an index for individual responses for each wave and averaged them between 2002 and 2012. The chronic conditions measure included a sum of seven diagnosed diseases: high blood pressure, diabetes, cancer, lung disease, heart disease, stroke, and arthritis, to capture lifelong history of conditions. We created this variable from wave 11 (2012) HRS data as it was closest temporally to the 2013 VMS.

\section{Methods}

LGCs were used to measure how SREs affect stability and change in depressive symptoms and psychiatric problems 
over a decade among older veterans. We chose this technique because LGCs capture both long-term levels and changes in our outcome variables over a large time span. Emerging literature on the intermittent nature of moral injury and the nature of LATR suggest both levels (intercepts) and changes (slopes) in our outcomes are important in the connections of SREs and mental health among older veterans (Davison et al., 2016; Litz et al., 2009; Maguen \& Litz, 2012).

Using a SEM approach and Mplus software, LGCs established individual-level trajectories of depressive symptoms and psychiatric problems, respectively (2002-2012) and further assessed how individuals varied from the average trajectory based on important covariates, including SREs.

We explored the baseline trajectories of depressive symptoms and psychiatric problems, to establish model fit. We then ran a series of five models using depressive symptoms and psychiatric problems as outcomes, respectively, to see how covariates alter their levels and rate of change. The general unconditional, Level 1 equation used for the baseline trajectories of depressive symptoms and psychiatric problems is:

$$
y_{i t}=\alpha_{y i}+\beta_{y i} \lambda_{y t}+\varepsilon_{y i t}
$$

where $y_{i t}$ is a vector of repeated measures, $\alpha_{y i}$ is a vector of latent intercepts, $\beta_{y i}$ is a vector of latent slopes, $\lambda_{y t}$ is a vector of fixed/freed loadings representing time, and $\varepsilon_{i t}$ is a vector of disturbance terms assumed to have equal variances.

The conditional, Level 2 equations used for the five models that include covariates is:

$$
\begin{aligned}
& \alpha_{y i}=\mu_{\alpha y}+\gamma_{\alpha y 1} x_{1 i}+\zeta_{y \alpha_{i}} \\
& \beta_{y i}=\mu_{\beta y}+\gamma_{\beta y 1} x_{1 i}+\zeta_{y \beta_{i}}
\end{aligned}
$$

The first of the five conditional models examined the bivariate impact of combat and sociodemographic controls on the level and change in both outcome measures. The second model added exposure to death, the third model added marital disruption, and the fourth model added physical health but removed marital disruption. Marital disruption and physical health are the two life-course pathways included to understand the indirect impacts of SREs on later life mental health, so we evaluated them separately (Models 3 and 4) in order to understand how they independently influence the relationship between SREs and mental health. The fifth model is a full model including all study variables.

A maximum likelihood estimator was used for the depressive symptom and psychiatric problem LGCs; however, a logit link function was used for the binary dependent variable of psychiatric problems. In the SEM framework, categorical observed dependent variables are translated to a linear model through continuous latent response variables (usually denoted $y^{*}$ ) capturing the binary observed variable/s. The regression coefficients are thus regular linear coefficients, and can be interpreted in terms of the standard deviation of the latent response variable y* (Masyn, Petras, \& Liu, 2014). All results were standardized for consistency of interpretation across measures. The standardized coefficients for depressive symptoms can be interpreted as a standard deviation increase/decrease in the CESD items over time. The standardized coefficients for psychiatric problems can be interpreted in terms of a standard deviation increase/decrease in the latent continuous dependent variables capturing the binary variables of psychiatric problem diagnosis over time.

Since the 2013 VMS variables were linked to a decade of information leading up to Wave 11 of the HRS, Wave 11 (2012) serves as the latent intercept. Thus, the interpretation of the intercept is the average value of the observed/ latent outcome variable in 2012. The growth curves were estimated using a linear specification, with factor loadings fixed at $-5,-4,-3,-2,-1$, and 0 for each year starting in 2002 and leading up to 2012. The negative factor loadings simply aid ease of interpretation, since change is more intuitively thought of as moving forward over historical time. Positive values for the latent slope can be interpreted as increases in the dependent variables from 2002 to 2012. For more discussion of time metrics and factor loadings in LGCs, see Bollen and Curran (2005).

\section{Results}

\section{Descriptive Statistics}

Table 1 shows the unweighted descriptive statistics for the variables in the models. Examination of SREs shows that less than $30 \%$ of the sample saw combat or were exposed to death, respectively. Additional analyses (not shown) revealed that exposure to combat did not necessarily expose veterans to death ( $31 \%$ not exposed), highlighting heterogeneity in SREs. Ninety-six percent of the sample was male and $85.4 \%$ were White. A minority of wartime veterans served during WWII $(12.6 \%)$ and the Korean War $(22.1 \%)$, and the most common type of wartime service was during the Vietnam War $(28.4 \%)$, with all others being peacetime veterans. The respondents had an average of 13.7 years of education and 5.1 total years of military service. On average, the respondents reported 0.9 FLs and 2.4 chronic conditions, while $12.0 \%$ had ever divorced and $12.5 \%$ were widowed. Although average CESD levels never exceeded 1.1 depressive symptoms, between $8 \%$ and $14 \%$ of veterans reported diagnosed psychiatric problems. Between 2002 and 2012, both depressive symptoms and psychiatric problems increased slightly, suggesting that mental health worsens in later ages for veterans (Mirowsky \& Ross, 1992), consistent with general older adult samples.

\section{Baseline Models}

Results from the baseline models suggest that linear trajectories fit the data well for both outcomes (models not shown). Depressive symptoms trajectories had a good overall 
Table 1. Unweighted Descriptive Statistics (Means and Standard Deviations)

\begin{tabular}{|c|c|c|c|}
\hline & Mean/\% & $S D$ & $N$ \\
\hline Combat & $27.4 \%$ & - & 1,662 \\
\hline Death & $27.0 \%$ & - & 1,662 \\
\hline Male & $96.0 \%$ & - & 1,662 \\
\hline White & $85.4 \%$ & - & 1,662 \\
\hline Education (years) & 13.65 & 2.40 & 1,662 \\
\hline Service duration (years) & 5.06 & 6.56 & 1,662 \\
\hline Ever divorced & $12.0 \%$ & - & 1,662 \\
\hline Ever widowed & $12.5 \%$ & - & 1,662 \\
\hline Average functional limitations & 0.85 & 1.07 & 1,662 \\
\hline No. of chronic conditions ever & 2.37 & 1.40 & 1,662 \\
\hline WWII & $12.6 \%$ & - & 1,662 \\
\hline Korea & $22.1 \%$ & - & 1,662 \\
\hline Vietnam & $28.4 \%$ & - & 1,662 \\
\hline CESD (Wave 6) & 0.80 & 1.46 & 1,152 \\
\hline CESD (Wave 7) & 0.76 & 1.42 & 1,326 \\
\hline CESD (Wave 8) & 0.81 & 1.42 & 1,353 \\
\hline CESD (Wave 9) & 0.89 & 1.52 & 1,378 \\
\hline CESD (Wave 10) & 0.93 & 1.63 & 1,634 \\
\hline CESD (Wave 11) & 1.06 & 1.71 & 1,662 \\
\hline Psychiatric problem (Wave 6) & $7.8 \%$ & - & 1,195 \\
\hline Psychiatric problem (Wave 7) & $9.1 \%$ & - & 1,364 \\
\hline Psychiatric problem (Wave 8) & $10.0 \%$ & - & 1,366 \\
\hline Psychiatric problem (Wave 9) & $11.1 \%$ & - & 1,391 \\
\hline Psychiatric problem (Wave 10) & $13.2 \%$ & - & 1,646 \\
\hline Psychiatric problem (Wave 11) & $14.2 \%$ & - & 1,662 \\
\hline
\end{tabular}

model fit $\left[\chi^{2}=32.71(p<.01), d f=16\right.$; Tucker-Lewis Index $(\mathrm{TLI})=0.99$; Comparative Fit Index $(\mathrm{CFI})=0.99$; Root Mean Square Error of Approximation (RMSEA) $=0.03$ ], as did those for psychiatric problems $\left(\chi^{2}=57.74 \mathrm{NS}, d f=58\right)$. For depressive symptoms, the mean of the latent intercept in 2012 was $0.77(p<.001)$ and the mean of the latent slope was $0.20(p<.001)$. For psychiatric problems, the mean of the latent intercept was set to zero for standardization (the intercept value was captured through the model estimated thresholds which were significantly greater than zero), and the mean of the latent slope was $4.03(p<.001)$. These results suggest that, consistent with $\mathrm{H} 1$ and Table 1, there were significant levels/prevalence of depressive symptoms and psychiatric problems and a significant amount of growth, on average, in poor mental health over the decade among veterans.

\section{Depressive Symptoms}

In Table 2, Model 1 shows that combat does not have a significant intercept or slope effect, so unlike H2, it does not have far reaching connections to depressive symptoms across later life. White veterans had a lower depressive symptom intercept $(-.24 ; p<.01)$ on average, but had a faster rate of increase of symptoms $(.33 ; p<.05)$ compared with veterans of other races. Male veterans had a lower depressive symptom intercept $(-.34 ; P<.05)$ on average, but there was no difference in the slope when compared with females. Veterans with more education experienced a $.07(p<.001)$ standard deviation decrease in depressive symptoms. In terms of period of service, veterans who participated in the Korean War experienced a .16 $(p<.05)$ standard deviation decrease in depressive symptoms, but had no difference in slope when compared with peacetime veterans. WWII and Vietnam veterans each had nonsignificant intercepts; however, those active in WWII had a faster rate of increase of depressive symptoms $(.35 ; p<.05)$, consistent with findings from Wilmoth and colleagues (2010), while Vietnam veterans had a slower rate of decrease of depressive symptoms $(-.29 ; p<.05)$ compared with peacetime veterans.

Moving to Model 2, the effect of combat remained nonsignificant here and in all subsequent models. Consistent with $\mathrm{H} 2$, exposure to death was associated with a .16 ( $p<$ .05 ) standard deviation increase in depressive symptoms, but similar to combat, the slope for exposure to death was not significant in any of the models. These findings suggest that the veteran long-term risk for depressive symptoms is not increased for those serving in combat zones, but rather by those exposed to death. The effect of exposure to death remained significant and essentially unchanged in Model 3 when marital disruption was included, such that those veterans experienced a $.16(p<.05)$ standard deviation increase in depressive symptoms net of marital disruptions, inconsistent with $\mathrm{H} 3$. However, the addition of physical health variables in Model 4 reduced the effect of exposure to death to nonsignificance and it remained nonsignificant in Model 5. Veterans with a greater average number of functional limitations experienced a $.47(p<$ .001) standard deviation increase in depressive symptoms, consistent with H3. This suggests that physical health may be an important pathway through which exposure to death increases self-reported depressive symptoms for veterans as they age.

\section{Psychiatric Problems}

The results for psychiatric problems are included in Table 3. Model 1 shows that consistent with $\mathrm{H} 2$, veterans exposed to combat experienced a $.07(p<.005)$ standard deviation increase in the latent continuous dependent variable capturing the binary variable of psychiatric problems, on average, with a $.15(p<.10)$ standard deviation growth over time.

Male veterans had a lower psychiatric problem intercept $(-.17 ; p<.05)$ on average, with a faster rate of increase over time compared with females $(.85 ; p<.001)$. Each year of education had a $.03(p<.05)$ standard deviation growth over time. For period of service, veterans who participated in WWII and the Korean War experienced a $.65(p<.001)$ and a $.66(p<.001)$ standard deviation decrease, respectively, in the latent continuous intercept variable capturing the binary psychiatric problems variables, but had no 
Table 2. Standardized Coefficients for Depressive Symptoms (Models $1-5 ; N=1,662$ )

\begin{tabular}{|c|c|c|c|c|c|c|c|c|c|c|}
\hline \multirow[b]{2}{*}{ Outcomes } & \multicolumn{2}{|c|}{$\begin{array}{l}\text { Model 1: combat } \\
+ \text { demographic } \\
\text { characteristics }\end{array}$} & \multicolumn{2}{|c|}{$\begin{array}{l}\text { Model 2: M1 + } \\
\text { death }\end{array}$} & \multicolumn{2}{|c|}{$\begin{array}{l}\text { Model 3: M2 + } \\
\text { marital status }\end{array}$} & \multicolumn{2}{|c|}{$\begin{array}{l}\text { Model 4: M3 + } \\
\text { physical health }\end{array}$} & \multicolumn{2}{|c|}{$\begin{array}{l}\text { Model 5: full } \\
\text { models }\end{array}$} \\
\hline & CESD $\alpha$ & CESD $\beta$ & CESD $\alpha$ & CESD $\beta$ & CESD $\alpha$ & CESD $\beta$ & CESD $\alpha$ & CESD $\beta$ & CESD $\alpha$ & CESD $\beta$ \\
\hline Combat & $\begin{array}{c}0.09 \\
(0.07)\end{array}$ & $\begin{array}{c}0.06 \\
(0.11)\end{array}$ & $\begin{array}{c}0.00 \\
(0.08)\end{array}$ & $\begin{array}{c}0.02 \\
(0.13)\end{array}$ & $\begin{array}{l}-0.01 \\
(0.08)\end{array}$ & $\begin{array}{c}0.00 \\
(0.13)\end{array}$ & $\begin{array}{l}-0.01 \\
(0.07)\end{array}$ & $\begin{array}{c}0.01 \\
(0.13)\end{array}$ & $\begin{array}{l}-0.01 \\
(0.07)\end{array}$ & $\begin{array}{c}0.00 \\
(0.13)\end{array}$ \\
\hline Death & - & - & $\begin{array}{c}0.16^{*} \\
(0.08)\end{array}$ & $\begin{array}{c}0.08 \\
(0.13)\end{array}$ & $\begin{array}{c}0.16^{*} \\
(0.08)\end{array}$ & $\begin{array}{c}0.09 \\
(0.13)\end{array}$ & $\begin{array}{c}0.03 \\
(0.07)\end{array}$ & $\begin{array}{c}0.05 \\
(0.13)\end{array}$ & $\begin{array}{c}0.04 \\
(0.07)\end{array}$ & $\begin{array}{c}0.05 \\
(0.13)\end{array}$ \\
\hline Male & $\begin{array}{c}-0.34 * \\
(0.15)\end{array}$ & $\begin{array}{c}0.25 \\
(0.27)\end{array}$ & $\begin{array}{l}-0.34 * \\
(0.15)\end{array}$ & $\begin{array}{c}0.25 \\
(0.27)\end{array}$ & $\begin{array}{l}-0.24 \\
(0.14)\end{array}$ & $\begin{array}{c}0.26 \\
(0.27)\end{array}$ & $\begin{array}{l}-0.18 \\
(0.13)\end{array}$ & $\begin{array}{c}0.23 \\
(0.26)\end{array}$ & $\begin{array}{l}-0.11 \\
(0.13)\end{array}$ & $\begin{array}{c}0.22 \\
(0.27)\end{array}$ \\
\hline White & $\begin{array}{l}-0.24 * * \\
(0.08)\end{array}$ & $\begin{array}{c}0.33^{*} \\
(0.16)\end{array}$ & $\begin{array}{l}-0.23 * * \\
(0.08)\end{array}$ & $\begin{array}{c}0.33^{*} \\
(0.16)\end{array}$ & $\begin{array}{l}-0.17^{*} \\
(0.08)\end{array}$ & $\begin{array}{c}0.33^{*} \\
(0.16)\end{array}$ & $\begin{array}{l}-0.09 \\
(0.08)\end{array}$ & $\begin{array}{l}0.42 * * \\
(0.15)\end{array}$ & $\begin{array}{l}-0.05 \\
(0.08)\end{array}$ & $\begin{array}{l}0.40 * * \\
(0.15)\end{array}$ \\
\hline Education (years) & $\begin{array}{l}-0.07 * * * \\
(0.01)\end{array}$ & $\begin{array}{l}-0.00 \\
(0.02)\end{array}$ & $\begin{array}{l}-0.07 * * * \\
(0.01)\end{array}$ & $\begin{array}{l}-0.00 \\
(0.02)\end{array}$ & $\begin{array}{l}-0.07 * * * \\
(0.01)\end{array}$ & $\begin{array}{l}-0.00 \\
(0.02)\end{array}$ & $\begin{array}{l}-0.03 * * \\
(0.01)\end{array}$ & $\begin{array}{c}0.01 \\
(0.02)\end{array}$ & $\begin{array}{l}-0.03 * * \\
(0.01)\end{array}$ & $\begin{array}{c}0.01 \\
(0.02)\end{array}$ \\
\hline $\begin{array}{l}\text { Service duration } \\
\text { (years) }\end{array}$ & $\begin{array}{c}0.01 \\
(0.01)\end{array}$ & $\begin{array}{c}0.01 \\
(0.01)\end{array}$ & $\begin{array}{c}0.00 \\
(0.01)\end{array}$ & $\begin{array}{c}0.01 \\
(0.01)\end{array}$ & $\begin{array}{c}0.00 \\
(0.00)\end{array}$ & $\begin{array}{c}0.01 \\
(0.01)\end{array}$ & $\begin{array}{c}0.00 \\
(0.00)\end{array}$ & $\begin{array}{c}0.01 \\
(0.01)\end{array}$ & $\begin{array}{c}0.00 \\
(0.00)\end{array}$ & $\begin{array}{c}0.01 \\
(0.01)\end{array}$ \\
\hline WWII & $\begin{array}{c}0.03 \\
(0.10)\end{array}$ & $\begin{array}{c}0.35^{*} \\
(0.15)\end{array}$ & $\begin{array}{c}0.02 \\
(0.10)\end{array}$ & $\begin{array}{c}0.35^{*} \\
(0.15)\end{array}$ & $\begin{array}{l}-0.02 \\
(0.10)\end{array}$ & $\begin{array}{c}0.31 * \\
(0.15)\end{array}$ & $\begin{array}{l}-0.07 \\
(0.09)\end{array}$ & $\begin{array}{c}0.30^{*} \\
(0.15)\end{array}$ & $\begin{array}{l}-0.11 \\
(0.09)\end{array}$ & $\begin{array}{r}0.26^{+} \\
(0.15)\end{array}$ \\
\hline Korea & $\begin{array}{c}-0.16^{*} \\
(0.08)\end{array}$ & $\begin{array}{c}0.014 \\
(0.12)\end{array}$ & $\begin{array}{l}-0.16^{*} \\
(0.08)\end{array}$ & $\begin{array}{c}0.02 \\
(0.12)\end{array}$ & $\begin{array}{l}-0.16^{*} \\
(0.08)\end{array}$ & $\begin{array}{l}-0.00 \\
(0.02)\end{array}$ & $\begin{array}{l}-0.16^{*} \\
(0.07)\end{array}$ & $\begin{array}{c}0.01 \\
(0.12)\end{array}$ & $\begin{array}{l}-0.17^{*} \\
(0.07)\end{array}$ & $\begin{array}{l}-0.02 \\
(0.12)\end{array}$ \\
\hline Vietnam & $\begin{array}{c}0.04 \\
(0.07)\end{array}$ & $\begin{array}{l}-0.29^{*} \\
(0.13)\end{array}$ & $\begin{array}{c}0.03 \\
(0.07)\end{array}$ & $\begin{array}{l}-0.29^{*} \\
(0.13)\end{array}$ & $\begin{array}{c}0.03 \\
(0.07)\end{array}$ & $\begin{array}{l}-0.28 * \\
(0.13)\end{array}$ & $\begin{array}{c}0.06 \\
(0.07)\end{array}$ & $\begin{array}{l}-0.31 * * \\
(0.13)\end{array}$ & $\begin{array}{c}0.07 \\
(0.07)\end{array}$ & $\begin{array}{l}-0.30 * \\
(0.13)\end{array}$ \\
\hline Ever divorced & - & - & - & - & $\begin{array}{l}0.47 * * * \\
(0.09)\end{array}$ & $\begin{array}{c}0.02 \\
(0.15)\end{array}$ & - & - & $\begin{array}{l}0.28 * * * \\
(0.08)\end{array}$ & $\begin{array}{l}-0.08 \\
(0.15)\end{array}$ \\
\hline Ever widowed & - & - & - & - & $\begin{array}{l}0.38 * * * \\
(0.09)\end{array}$ & $\begin{array}{r}0.22^{+} \\
(0.14)\end{array}$ & - & - & $\begin{array}{l}0.35 * * \\
(0.08)\end{array}$ & $\begin{array}{c}0.21 \\
(0.13)\end{array}$ \\
\hline $\begin{array}{l}\text { Average functional } \\
\text { limitations }\end{array}$ & - & - & - & - & - & - & $\begin{array}{l}0.47 * * * \\
(0.02)\end{array}$ & $\begin{array}{l}0.14 * * \\
(0.05)\end{array}$ & $\begin{array}{l}0.46 * * * \\
(0.02)\end{array}$ & $\begin{array}{l}0.14^{* *} \\
(0.05)\end{array}$ \\
\hline $\begin{array}{l}\text { No. of chronic } \\
\text { conditions }\end{array}$ & - & - & - & - & - & - & $\begin{array}{l}-0.01 \\
(0.02)\end{array}$ & $\begin{array}{l}-0.02 \\
(0.04)\end{array}$ & $\begin{array}{l}-0.01 \\
(0.02)\end{array}$ & $\begin{array}{l}-0.02 \\
(0.04)\end{array}$ \\
\hline Intercept & $\begin{array}{l}2.26 * * * \\
(0.22)\end{array}$ & $\begin{array}{l}-0.38 \\
(0.39)\end{array}$ & $\begin{array}{l}2.25 * * * \\
(0.22)\end{array}$ & $\begin{array}{l}-0.38 \\
(0.39)\end{array}$ & $\begin{array}{l}1.93 * * * \\
(0.23)\end{array}$ & $\begin{array}{l}-0.43 \\
(0.40)\end{array}$ & $\begin{array}{l}1.08 * * * \\
(0.22)\end{array}$ & $\begin{array}{l}-0.65 \\
(0.41)\end{array}$ & $\begin{array}{l}0.88 * * * \\
(0.22)\end{array}$ & $\begin{array}{l}-0.63 \\
(0.41)\end{array}$ \\
\hline Variances & $\begin{array}{l}0.95 * * * \\
(0.01)\end{array}$ & $\begin{array}{l}0.93 * * * \\
(0.03)\end{array}$ & $\begin{array}{l}0.95 * * * \\
(0.01)\end{array}$ & $\begin{array}{l}0.93 * * * \\
(0.03)\end{array}$ & $\begin{array}{l}0.91 * * * \\
(0.02)\end{array}$ & $\begin{array}{l}0.93 * * * \\
(0.03)\end{array}$ & $\begin{array}{l}0.71 * * * \\
(0.02)\end{array}$ & $\begin{array}{l}0.91 * * * \\
(0.03)\end{array}$ & $\begin{array}{l}0.69 * * * \\
(0.02)\end{array}$ & $\begin{array}{l}0.91 * * * \\
(0.03)\end{array}$ \\
\hline$\chi^{2}(d f)$ & \multicolumn{2}{|c|}{$74.57(48)$} & \multicolumn{2}{|c|}{$81.07(52)$} & \multicolumn{2}{|c|}{$95.70(60)$} & \multicolumn{2}{|c|}{$88.74(60)$} & \multicolumn{2}{|c|}{$103.35(68)$} \\
\hline Probability & \multicolumn{2}{|c|}{0.008} & \multicolumn{2}{|c|}{0.006} & \multicolumn{2}{|c|}{0.002} & \multicolumn{2}{|c|}{0.009} & \multicolumn{2}{|c|}{0.004} \\
\hline TLI & \multicolumn{2}{|c|}{0.990} & \multicolumn{2}{|c|}{0.987} & \multicolumn{2}{|c|}{0.985} & \multicolumn{2}{|c|}{0.989} & \multicolumn{2}{|c|}{0.986} \\
\hline CFI & \multicolumn{2}{|c|}{0.990} & \multicolumn{2}{|c|}{0.991} & \multicolumn{2}{|c|}{0.989} & \multicolumn{2}{|c|}{0.992} & \multicolumn{2}{|c|}{0.990} \\
\hline RMSEA & \multicolumn{2}{|c|}{0.018} & \multicolumn{2}{|c|}{0.018} & \multicolumn{2}{|c|}{0.019} & \multicolumn{2}{|c|}{0.017} & \multicolumn{2}{|c|}{0.018} \\
\hline BIC & \multicolumn{2}{|c|}{28555.75} & 2856 & 5.09 & 2853 & 6.55 & 2816 & 3.05 & 2814 & 8.84 \\
\hline
\end{tabular}

Notes: Standard errors in parentheses.

Tucker-Lewis Index (TLI); Comparative Fit Index (CFI); Root Mean Square Error of Approximation (RMSEA); Bayesian Information Criterion (BIC).

${ }^{+} p \leq .1 .{ }^{*} p \leq .05 .{ }^{* *} p \leq .01 .{ }^{* * *} p \leq .001$.

difference in slope when compared with peacetime veterans. Although the Vietnam War did not have a significant intercept; the veterans of that war had slower rate growth of psychiatric problems $(-.40 ; p<.001)$ compared with peacetime veterans. Model 2 shows that Vietnam veterans are at increased risk for psychiatric problems in the intercept $(.28, p<.001)$, and interestingly, WWII veterans in this model also saw increased accumulation over time (.42, $p<.01)$.

In Model 2, the introduction of exposure to death increased the significance of combat on the intercept; however, combat's effect incurred a change in direction, such that once death was included veterans exposed to combat experienced a decrease in the latent intercept variable capturing psychiatric problems. The slope of combat became nonsignificant. Veterans exposed to death experienced a $.27(p<.001)$ standard deviation increase in the latent continuous dependent variable capturing the binary variable of psychiatric problems, on average, with a .29 ( $p$ $<.05)$ standard deviation growth over time. This suggests that exposure to death places veterans at a cumulatively increased risk of psychiatric problems in later life. With 
Table 3. Standardized Coefficients for Psychiatric Problems (Models $1-5 ; N=1,662$ )

\begin{tabular}{|c|c|c|c|c|c|c|c|c|c|c|}
\hline \multirow[b]{2}{*}{ Outcomes } & \multicolumn{2}{|c|}{$\begin{array}{l}\text { Model 1: combat } \\
\text { + demographic } \\
\text { characteristics }\end{array}$} & \multicolumn{2}{|c|}{ Model 2: M1 + death } & \multicolumn{2}{|c|}{$\begin{array}{l}\text { Model 3: M2 + } \\
\text { marital status }\end{array}$} & \multicolumn{2}{|c|}{$\begin{array}{l}\text { Model 4: M3 + physical } \\
\text { health }\end{array}$} & \multicolumn{2}{|c|}{ Model 5: Full Models } \\
\hline & $\begin{array}{l}\text { PsychProb } \\
\alpha\end{array}$ & $\begin{array}{l}\text { PsychProb } \\
\beta\end{array}$ & $\begin{array}{l}\text { PsychProb } \\
\alpha\end{array}$ & $\begin{array}{l}\text { PsychProb } \\
\beta\end{array}$ & $\begin{array}{l}\text { PsychProb } \\
\alpha\end{array}$ & $\begin{array}{l}\text { PsychProb } \\
\beta\end{array}$ & $\begin{array}{l}\text { PsychProb } \\
\alpha\end{array}$ & $\begin{array}{l}\text { PsychProb } \\
\beta\end{array}$ & $\begin{array}{l}\text { PsychProb } \\
\alpha\end{array}$ & $\begin{array}{l}\text { PsychProb } \\
\beta\end{array}$ \\
\hline Combat & $\begin{array}{c}0.07 * \\
(0.03)\end{array}$ & $\begin{array}{r}0.15^{+} \\
(0.09)\end{array}$ & $\begin{array}{l}-0.22 * * * \\
(0.05)\end{array}$ & $\begin{array}{c}0.02 \\
(0.15)\end{array}$ & $\begin{array}{r}0.08^{+} \\
(0.05)\end{array}$ & $\begin{array}{l}0.33 * * \\
(0.12)\end{array}$ & $\begin{array}{l}0.29 * * * \\
(0.04)\end{array}$ & $\begin{array}{c}0.21 \\
(0.14)\end{array}$ & $\begin{array}{l}0.15 * * * \\
(0.03)\end{array}$ & $\begin{array}{l}0.51 * * * \\
(0.13)\end{array}$ \\
\hline Death & - & - & $\begin{array}{l}0.27^{* * *} \\
(0.04)\end{array}$ & $\begin{array}{c}0.29 * \\
(0.15)\end{array}$ & $\begin{array}{l}0.20 * * * \\
(0.05)\end{array}$ & $\begin{array}{c}0.07 \\
(0.14)\end{array}$ & $\begin{array}{c}0.01 \\
(0.04)\end{array}$ & $\begin{array}{l}0.42 * * * \\
(0.11)\end{array}$ & $\begin{array}{l}0.23 * * * \\
(0.03)\end{array}$ & $\begin{array}{c}0.04 \\
(0.18)\end{array}$ \\
\hline Male & $\begin{array}{c}-0.17 * \\
(0.07)\end{array}$ & $\begin{array}{l}0.85 * * * \\
(0.13)\end{array}$ & $\begin{array}{l}-0.28 * * * \\
(0.05)\end{array}$ & $\begin{array}{l}0.71 * * * \\
(0.16)\end{array}$ & $\begin{array}{l}-0.51 * * * \\
(0.09)\end{array}$ & $\begin{array}{l}0.44 * * \\
(0.17)\end{array}$ & $\begin{array}{l}-0.54 * * \\
(0.05)\end{array}$ & $\begin{array}{c}0.21 \\
(0.19)\end{array}$ & $\begin{array}{l}-0.31 * * * \\
(0.05)\end{array}$ & $\begin{array}{c}0.40 \\
(0.26)\end{array}$ \\
\hline White & $\begin{array}{c}-0.05 \\
(0.03)\end{array}$ & $\begin{array}{c}0.08 \\
(0.18)\end{array}$ & $\begin{array}{l}-0.11 * * \\
(0.03)\end{array}$ & $\begin{array}{c}0.22 \\
(0.14)\end{array}$ & $\begin{array}{c}-0.05 \\
(0.05)\end{array}$ & $\begin{array}{c}0.04 \\
(0.11)\end{array}$ & $\begin{array}{l}0.23 * * * \\
(0.04)\end{array}$ & $\begin{array}{l}0.49 * * \\
(0.15)\end{array}$ & $\begin{array}{l}0.33 * * \\
(0.03)\end{array}$ & $\begin{array}{c}0.40^{*} \\
(0.17)\end{array}$ \\
\hline $\begin{array}{l}\text { Education } \\
\text { (years) }\end{array}$ & $\begin{array}{c}-0.00 \\
(0.01)\end{array}$ & $\begin{array}{c}0.03 * \\
(0.01)\end{array}$ & $\begin{array}{c}0.00 \\
(0.01)\end{array}$ & $\begin{array}{l}0.05 * \\
(0.02)\end{array}$ & $\begin{array}{c}0.01 \\
(0.01)\end{array}$ & $\begin{array}{l}0.05 * * \\
(0.02)\end{array}$ & $\begin{array}{c}-0.00 \\
(0.01)\end{array}$ & $\begin{array}{c}-0.04 * \\
(0.02)\end{array}$ & $\begin{array}{c}0.00 \\
(0.01)\end{array}$ & $\begin{array}{c}0.04 \\
(0.02)\end{array}$ \\
\hline $\begin{array}{l}\text { Service } \\
\text { duration } \\
\text { (years) }\end{array}$ & $\begin{array}{c}-0.00 \\
(0.00)\end{array}$ & $\begin{array}{c}-0.01 \\
(0.01)\end{array}$ & $\begin{array}{l}0.01 * * * \\
(0.00)\end{array}$ & $\begin{array}{l}-0.00 \\
(0.01)\end{array}$ & $\begin{array}{c}0.00 \\
(0.00)\end{array}$ & $\begin{array}{c}-0.01 \\
(0.01)\end{array}$ & $\begin{array}{l}0.01 * * * \\
(0.00)\end{array}$ & $\begin{array}{r}0.02^{+} \\
(0.01)\end{array}$ & $\begin{array}{l}0.01 * * * \\
(0.00)\end{array}$ & $\begin{array}{c}0.00 \\
(0.01)\end{array}$ \\
\hline WWII & $\begin{array}{l}-0.65 * * * \\
(0.05)\end{array}$ & $\begin{array}{c}0.07 \\
(0.17)\end{array}$ & $\begin{array}{l}-0.28 * * \\
(0.05)\end{array}$ & $\begin{array}{l}0.42 * * \\
(0.16)\end{array}$ & $\begin{array}{l}-0.72 * * * \\
(0.07)\end{array}$ & $\begin{array}{l}0.46 * * \\
(0.15)\end{array}$ & $\begin{array}{l}-0.63 * * * \\
(0.05)\end{array}$ & $\begin{array}{c}0.13 \\
(0.21)\end{array}$ & $\begin{array}{l}-0.64 * * * \\
(0.06)\end{array}$ & $\begin{array}{c}-0.02 \\
(0.32)\end{array}$ \\
\hline Korea & $\begin{array}{l}-0.66 * * \\
(0.03)\end{array}$ & $\begin{array}{c}-0.11 \\
(0.15)\end{array}$ & $\begin{array}{l}-0.36 * * \\
(0.04)\end{array}$ & $\begin{array}{c}0.04 \\
(0.14)\end{array}$ & $\begin{array}{l}-0.74 * * * \\
(0.06)\end{array}$ & $\begin{array}{c}-0.23 \\
(0.16)\end{array}$ & $\begin{array}{l}-0.70 * * * \\
(0.04)\end{array}$ & $\begin{array}{c}-0.27 \\
(0.25)\end{array}$ & $\begin{array}{l}-0.64 * * * \\
(0.03)\end{array}$ & $\begin{array}{c}-0.52 * \\
(0.24)\end{array}$ \\
\hline Vietnam & $\begin{array}{c}-0.01 \\
(0.04)\end{array}$ & $\begin{array}{l}-0.40 * * * \\
(0.10)\end{array}$ & $\begin{array}{l}0.28 * * * \\
(0.04)\end{array}$ & $\begin{array}{c}0.13 \\
(0.14)\end{array}$ & $\begin{array}{c}-0.04 \\
(0.05)\end{array}$ & $\begin{array}{l}-0.30 * * \\
(0.11)\end{array}$ & $\begin{array}{c}0.02 \\
(0.04)\end{array}$ & $\begin{array}{c}-0.19^{+} \\
(0.11)\end{array}$ & $\begin{array}{l}0.27 * * \\
(0.03)\end{array}$ & $\begin{array}{c}-0.33^{+} \\
(0.17)\end{array}$ \\
\hline Ever divorced & - & - & - & - & $\begin{array}{l}0.25 * * * \\
(0.05)\end{array}$ & $\begin{array}{c}-0.24 * \\
(0.10)\end{array}$ & - & - & $\begin{array}{l}0.35 * * \\
(0.04)\end{array}$ & $\begin{array}{c}0.14 \\
(0.18)\end{array}$ \\
\hline Ever widowed & - & - & - & - & $\begin{array}{l}-0.21 * * * \\
(0.06)\end{array}$ & $\begin{array}{c}-0.18 \\
(0.11)\end{array}$ & - & - & $\begin{array}{l}0.14 * * \\
(0.05)\end{array}$ & $\begin{array}{l}0.49 * * \\
(0.17)\end{array}$ \\
\hline $\begin{array}{l}\text { Average } \\
\text { functional } \\
\text { limitations }\end{array}$ & - & - & - & - & - & - & $\begin{array}{l}0.27 * * * \\
(0.01)\end{array}$ & $\begin{array}{l}-0.25 * * * \\
(0.07)\end{array}$ & $\begin{array}{l}0.26 * * * \\
(0.01)\end{array}$ & $\begin{array}{c}-0.00 \\
(0.09)\end{array}$ \\
\hline $\begin{array}{l}\text { No. of chronic } \\
\text { conditions }\end{array}$ & - & - & - & - & - & - & $\begin{array}{l}0.12 * * * \\
(0.01)\end{array}$ & $\begin{array}{r}0.09^{+} \\
(0.05)\end{array}$ & $\begin{array}{l}0.13 * * * \\
(0.01)\end{array}$ & $\begin{array}{l}0.14 * * \\
(0.06)\end{array}$ \\
\hline Intercept & $\begin{array}{c}0.00 \\
(999.0)\end{array}$ & $\begin{array}{c}0.07 \\
(0.85)\end{array}$ & $\begin{array}{c}0.00 \\
(999.0)\end{array}$ & $\begin{array}{l}-0.71^{+} \\
(0.38)\end{array}$ & $\begin{array}{c}0.00 \\
(999.0)\end{array}$ & $\begin{array}{c}0.25 \\
(0.32)\end{array}$ & $\begin{array}{c}0.00 \\
(999.0)\end{array}$ & $\begin{array}{r}0.82^{+} \\
(0.43)\end{array}$ & $\begin{array}{c}0.00 \\
(999.0)\end{array}$ & $\begin{array}{l}-0.91 \\
(0.65)\end{array}$ \\
\hline Variances & $\begin{array}{l}0.90 * * * \\
(0.01)\end{array}$ & $\begin{array}{l}0.93 * * * \\
(0.02)\end{array}$ & $\begin{array}{l}0.91 * * * \\
(0.01)\end{array}$ & $\begin{array}{l}0.92 * * * \\
(0.02)\end{array}$ & $\begin{array}{l}0.83 * * * \\
(0.02)\end{array}$ & $\begin{array}{l}0.89 * * \\
(0.02)\end{array}$ & $\begin{array}{l}0.74 * * * \\
(0.01)\end{array}$ & $\begin{array}{l}0.80 * * * \\
(0.04)\end{array}$ & $\begin{array}{l}0.68 * * * \\
(0.01)\end{array}$ & $\begin{array}{l}0.79 * * * \\
(0.06)\end{array}$ \\
\hline$\chi^{2}(d f)$ & & - & & & & - & & & - & \\
\hline Probability & & - & & & & - & - & & - & \\
\hline TLI & & - & & & & - & & - & - & - \\
\hline CFI & & - & & & & - & & - & & - \\
\hline RMSEA & & - & & - & & - & - & - & - & - \\
\hline BIC & 25 & 4.19 & 25 & 3.81 & & 67.18 & 241 & 9.77 & 2448 & .728 \\
\hline
\end{tabular}

Notes: Standard errors in parentheses.

Tucker-Lewis Index (TLI); Comparative Fit Index (CFI); Root Mean Square Error of Approximation (RMSEA); Bayesian Information Criterion (BIC).

${ }^{*} p \leq .1 .{ }^{*} p \leq .05 . * * p \leq .01 . * * * \leq .001$.

the addition of marital disruption in Model 3, the effect of exposure to death remained significant $(.2 ; p<.001)$, but the magnitude and significance of exposure to combat were both reduced $(.08 ; p<.10)$, suggesting the effect of combat exposure on psychiatric problems works partially through marital status, consistent with $\mathrm{H} 3$. Conversely, the addition of physical health variables in Model 4 brought the effect of exposure to death to nonsignificance for the intercept and increased the significance and magnitude of the slope. In the full model (Model 5), veterans exposed to combat experienced a $0.15(p<.001)$ standard deviation increase in the latent continuous dependent variable capturing psychiatric problems at baseline, with this effect increasing over the decade $(.51, p<.001)$. Veterans exposed to death experienced a $.23(p<.001)$ standard deviation increase in the intercept. These findings suggest that exposures to combat 
and death pose independent and direct mental health risks for older veterans net of covariates. It also suggests that marital disruption (divorce and widowhood) and physical health (functional limitations and number of chronic conditions) are important in the indirect connection between exposure to combat and death and psychiatric problems over time, but that these mediating pathways are nuanced for this outcome.

\section{Discussion}

We used LGCs to examine 10-year trajectories of depressive symptoms and psychiatric problems in order to estimate the effects of exposure to combat and exposure to death on the mental health of today's older veterans while testing three hypotheses: (H1) Older veterans will experience increasing amounts of depressive symptoms and psychiatric problems over time; (H2) older veterans with SREs, particularly exposure to death, will experience more depressive symptoms and psychiatric problems than veterans without these exposures; and (H3) physical health and marital disruption will account at least partially for the effects of SREs. Our overall finding was that SREs during military service had independent, lasting impacts on mental health of veterans and varied by outcome and life-course pathways. For depressive symptoms, the long-term mental health risk for veterans was driven by exposure to death, consistent with $\mathrm{H} 2$. Notably, the introduction of physical health reduced this effect to nonsignificance, which points to lifetime physical health as an important pathway in this association, and corroborates H3. In the psychiatric problem models, both combat and exposure to death were linked to increased psychiatric problems. Although the independent introduction of marital disruption and physical health in Model 3 and Model 4 reduced the effect of combat and exposure to death, respectively, Model 5 indicates that SREs remain significant when analyzed together.

The analyses for depressive symptoms and psychiatric problems highlight the importance of life-course pathways in understanding SREs and mental health in elderly veterans. Marital disruption, for example, may represent a chain of risk (consistent with CAD theory) in which combat or exposure to death erodes chances of maintaining a successful marriage, which is protective of mental health. Also consistent with CAD theory, life-course disruption may be at play since military service creates disorder in the lives of those entering after establishing families and careers (Elder et al., 1994), emphasizing the potential to produce discontinuity that leads to worse post-service outcomes (Dechter \& Elder, 2004; London \& Wilmoth, 2006). Physical health was a particularly important pathway for exposure to death in our models, which makes sense considering that Taylor and colleagues (2016) found exposure to death is associated with FL increases among older veterans net of service-related disability. Since FLs are connected to self-reported psychological distress in later life (Taylor $\&$
Lynch, 2004), it is not surprising that physical health is a primary pathway between exposure to death and psychiatric problems.

Notable among the psychiatric problem models is that service duration in years is a statistically significant covariate. Duration of military service is an important characteristic along which the effect of military service may vary (Wolf, Wing, \& Lopoo, 2013), and it can be used as a proxy for the life-course disruption hypothesis (Teachman, 2013). Prolonged military service within the cohorts in our analysis may provide enough disruption in the life course to become relevant for later life psychiatric problems that capture more serious, doctor diagnosed threats to health, as opposed to depressive symptoms which are not a diagnosis of depression. The relevance of service duration to psychiatric problems is bolstered by the fact that service members are initially selected into the military on good mental health (London, Burgard, \& Wilmoth, 2014), thus psychiatric problems come about through the degradation of mental health during or following military service. Although this article does not set out to address service duration, it is a military service characteristic that deserves more attention in the literature.

Importantly, this study demonstrates that exposure to combat does not work alone in driving poor mental health trajectories, and that exposure to death is a more robust risk marker for later outcomes. Exposure to death likely works as a proxy for particularly heavy combat and moral injury, which is correlated to stress-related mental health symptoms (Maguen \& Litz, 2012). What is more, the intermittent nature of moral injury allows us to begin to understand how increased depressive symptoms and psychiatric problems stemming from an earlier life experience may manifest and potentially accumulate in later life (Litz et al., 2009; Maguen \& Litz, 2012). This finding provides new insight into variation in veteran later life mental health, and holds important implications for timing health interventions and projecting service needs of the veterans utilizing the VA, especially those who were exposed to death. There is additional heterogeneity within combat experiences not captured here (e.g., prisoner of war), thus continuing to find and use specific SREs in veteran mental health research will further clarify the effect of differential exposures on the mental health of elderly veterans.

\section{Limitations}

Although our findings further knowledge on the implications of military service for later life mental health, our study is not without limitations. Estimating the consequences of military service is problematic due to selection issues-nonrandom selection into military, exit from military, and selective mortality-which merit caution in attributing causality to observed differences (Wolf et al., 2013). Our WWII cohort estimates come from a select group that survived until 2013 and participated in the VMS, which 
could indicate that they were more robust than the ones who did not survive to 2013, creating a bias in the results. The same can be said of members of the other war cohorts that did not survive to 2013. Although we cannot estimate bias introduced by mortality selection prior to the survey, we argue that our results are conservative if those with the worst health died prior to sample selection. It is also possible that early-life factors select veterans into different SREs-the "healthy warrior effect" (Larson, HighfillMcRoy, \& Booth-Kewley, 2008). We examined selection effects by predicting SREs using multiple childhood health and socioeconomic indicators available in the RAND HRS. None were significant so we did not include them in our final analyses. It is likely that samples including nonveterans would sustain greater bias because these variables may work more for service entry. Future studies should continue to examine and incorporate selection effects where possible (Wolf et al., 2013).

The measures of SREs are retrospective and selfreported, making them susceptible to recall bias. They may also be biased by existing health problems if veterans are seeking coverage from the VA (Frueh et al., 2005). The measure of combat used in our analyses is dichotomous; however, it would be beneficial to assess the severity of combat exposure in future research (Elder \& Clipp 1988). It is important to note that exposure to death does not guarantee participation in combat during military service. Additionally, we cannot establish when mental health problems began, thus tests of whether mental health risk was latent-emerging in later life-or persistent-experienced throughout adulthood-were beyond our scope. Finally, the HRS data are from conscription era veterans, so the results are not generalizable to the present AVF. Despite these limitations, our study adds to the small but growing understanding of military service and later life outcomes and, specifically, the mental health of elderly veterans. Our use of retrospective and longitudinal data allows examination of life-course implications, embracing the notion that military service is not unidimensional, nor experienced uniformly (Taylor et al., 2016; Wilmoth \& London, 2013), and provides new insight into the body of aging veteran literature that has yet to elaborate on the heterogeneity in military service experiences.

\section{Funding}

Research reported in this publication was supported by the National Institute on Aging of the National Institutes of Health under Award Number R36AG060214 (PI: Stephanie Ureña). The content is solely the responsibility of the authors and does not necessarily represent the official views of the National Institutes of Health.

\section{Acknowledgments}

Author contributions: S. Ureña planned the study, performed the statistical analyses, and drafted the article. M. G. Taylor also planned the study; supervised and assisted with statistical analyses; and contributed to drafting the article. B. L. Kail helped in creation of the dataset.

\section{Conflict of Interest}

There was no conflict of interest in the completion of this manuscript.

\section{References}

Barrett, A. E. (2000). Marital trajectories and mental health. Journal of Health and Social Behavior, 41, 451. doi:10.2307/2676297

Bollen, K. A., \& Curran, P. J. (2005). Latent curve models. Wiley Series in Probability and Statistics. doi:10.1002/0471746096

Burland, D., \& Lundquist, J. H. (2013). The best years of our lives: Military service and family relationships-A life course perspective. In J. M. Wilmoth \& A. S. London (Eds.), Life course perspectives on military service (pp. 165-184). New York, NY: Routledge.

Centers for Disease Control and Prevention. (2008). The state of mental health and aging in America issue brief 1: What do the data tell us? Atlanta, GA: National Association of Chronic Disease Directors. Retrieved from http://www.cdc.gov/aging/ pdf/mental_health.pdf

Cesur, R., Sabia, J. J., \& Tekin, E. (2013). The psychological costs of war: Military combat and mental health. Journal of Health Economics, 32, 51-65. doi:10.1016/j.jhealeco.2012.09.001

Davies, S. (2001). The long-term psychological effects of traumatic wartime experiences on older adults. Aging \& Mental Health, 5, 99-103. doi:10.1080/713650001

Davison, E. H., Kaiser, A. P., Spiro, A. III, Moye, J., King, L. A., \& King, D. W. (2016). From late-onset stress symptomatology to later-adulthood trauma reengagement in aging combat veterans: Taking a broader view. The Gerontologist, 56, 14-21. doi:10.1093/geront/gnv097

Dechter, A. R., \& Elder, Jr., G. H. (2004). World War II mobilization in men's work lives: Continuity or disruption for the middle class? American Journal of Sociology, 110, 761-793. doi:10.1086/422662

Elder, G. H., Jr. (1994). Time, human agency, and social change: Perspectives on the life course. Social Psychology Quarterly, 57, 4-15. doi:10.2307/2786971

Elder, G. H., Jr., \& Clipp, E. C. (1988). Combat experience, comradeship, and psychological health. In J. P. Wilson, Z. Harel, \& B. Kahana (Eds.), In Human Adaptation to Extreme Stress: From the Holocaust to Vietnam (pp. 131-156). Plenum Press: New York, NY.

Elder, G. H., Clipp, E. C., Brown, J. S., Martin, L. R., \& Friedman, H. W. (2009). The life-long mortality risks of World War II experiences. Research on Aging, 31, 391-412. doi:10.1177/0164027509333447

Elder, G. H., Jr., Pavalko, E. K., \& Clipp, E. C. (1992). Working with archival data: Studying lives. Sage University Paper Series on Quantitative Applications in the Social Sciences, series no. 07-088. Newbury Park, CA: Sage.

Elder, G. H., Jr., Shanahan, M. J., \& Clipp, E. C. (1994). When war comes to men's lives: Life-course patterns in family, work, and health. Psychology and Aging, 9, 5-16. doi:10.1037/0882-7974.9.1.5 
Elder, G. H., Jr., Shanahan, M. J., \& Clipp, E. C. (1997). Linking combat and physical health: The legacy of World War II in men's lives. American Journal of Psychiatry, 154, 330-336. doi:10.1177/0164027509333447

Ferraro, K. F., \& Shippee, T. P. (2009). Aging and cumulative inequality: How does inequality get under the skin? The Gerontologist, 49, 333-343. doi:10.1093/geront/gnp034

Frueh, B. C., Elhai, J. D., Grubaugh, A. L., Monnier, J., Kashdan, T. B., Sauvageot, J. A., ... Arana, G. W. (2005). Documented combat exposure of US veterans seeking treatment for combatrelated post-traumatic stress disorder. The British Journal of Psychiatry, 186, 467-472. doi:10.1192/bjp.186.6.467

George, L. K. (2003). Life course research. In J. T. Mortimer \& M. J. Shanahan (Eds.), Handbook of Life Course Research (pp. 671-680). New York: Springer.

George, L. K. (2007). Life course perspectives on social factors and mental illness. In W. R. Avison, J. D. McLeod, \& B.A. Pescosolido (Eds.), Mental health, social mirror (pp. 191-218). Springer: New York, NY.

Gimbel, C., \& Booth, A. (1994). Why does military combat experience adversely affect marital relations? Journal of Marriage and the Family, 56, 691-703. doi:10.2307/352879

Health and Retirement Study. (2012). Public use dataset. Produced and distributed by the University of Michigan with funding from the National Institute on Aging (grant number NIA U01AG009740): Ann Arbor, MI.

Gold, P. B., Engdahl, B. E., Eberly, R. E., Blake, R. J., Page, W. F., $\&$ Frueh, B. C. (2000). Trauma exposure, resilience, social support, and PTSD construct validity among former prisoners of war. Social Psychiatry and Psychiatric Epidemiology, 35, 36-42. doi:10.1007/s001270050006

Hunt, N., \& Robbins, I. (2001). The long-term consequences of war: The experience of World War II. Aging \& Mental Health, 5, 183-190. doi:10.1080/13607860120038393

Kaiser, A. P., Park, C. L., King, L. A., King, D. W., Schuster, J., Spiro, A. III, ... Keane, T. M. (2011). Long-term effects of coping with extreme stress: Longitudinal study of Vietnam-era repatriated prisoners of war. Journal of Traumatic Stress, 24, 680-690. doi:10.1002/jts.20695

Karlin, B. E., Trockel, M., Brown, G. K., Gordienko, M., Yesavage, J., \& Taylor, C. B. (2015). Comparison of the effectiveness of cognitive behavioral therapy for depression among older versus younger veterans: Results of a national evaluation. The Journals of Gerontology, Series B: Psychological Sciences and Social Sciences, 70, 3-12. doi:10.1093/geronb/gbt096

King, D. W., King, L. A., Park, C. L., Lee, L. O., Kaiser, A. P., Spiro, A., ... Keane, T. M. (2015). Positive adjustment among American repatriated prisoners of the Vietnam War modeling the long-term effects of captivity. Clinical Psychological Science, 3, 861-876. doi:10.1177/2167702614554448

Larson, G. E., Highfill-McRoy, R. M., \& Booth-Kewley, S. (2008). Psychiatric diagnoses in historic and contemporary military cohorts: Combat deployment and the healthy warrior effect. American Journal of Epidemiology, 167, 1269-1276. doi:10.1093/aje/kwn084

Litz, B. T., Stein, N., Delaney, E., Lebowitz, L., Nash, W. P., Silva, C., \& Maquen, S. (2009). Moral injury and moral repair in war veterans: A preliminary model and intervention strategy. Clinical Psychology Review, 29, 695-706. doi:10.1016/j.cpr.2009.07.003
London, A. S., Allen, E., \& Wilmoth, J. M. (2013). Veteran status, extramarital sex, and divorce: Findings from the 1992 National Health and Social Life Survey. Journal of Family Issues, 34, 1452-1473. doi:10.1177/0192513×12460510

London, A. S., Burgard, S. A., \& Wilmoth, J. M. (2014). Influence of veteran status, psychiatric diagnosis, and traumatic brain injury on inadequate sleep. The Journal of Sociology \& Social Welfare, $41,49-67$.

London, A. S., \& Wilmoth, J. M. (2006). Military service and (dis) continuity in the life course: Evidence on disadvantage and mortality from the Health and Retirement Study and the Study of Assets and Health Dynamics among the Oldest-Old. Research on Aging, 28, 135-159. doi:10.1177/0164027505281572

MacLean, A. (2013). A matter of life and death: Military service and health. In J. M. Wilmoth \& A. S. London (Eds.), Life course perspectives on military service (pp. 201-220). New York, NY: Routledge.

Maguen, S., \& Litz, B. (2012). Moral injury in veterans of war. PTSD Research Quarterly, 23, 1-6.

Masyn, K. E., Petras, H., \& Liu, W. (2014). Growth curve models with categorical outcomes. Encyclopedia of Criminology and Criminal Justice, 2013-2025. doi:10.1007/978-1-4614-5690-2_404

Mirowsky, J., \& Ross, C. E. (1992). Age and depression. Journal of Health and Social Behavior, 33, 187. doi:10.2307/2137349

National Institute on Aging. (2007). The Health \& Retirement Study: Growing older in America (NIH Publication No. 07-5757). Retrieved from http://www.nia.nih.gov/sites/default/ files/health_and_retirement_study.pdf

National Survey of Veterans. (2010). National survey of veterans, active duty service members, demobilized national guard and reserve members, family members, and surviving spouses. Retrieved from http://www.va.gov/SURVIVORS/docs/ NVSSurveyFinalWeightedReport.pdf

O'Rand, A. M. (1996). The precious and the precocious: Understanding cumulative disadvantage and cumulative advantage over the life course. The Gerontologist, 36, 230-238.

Park, C. L., Kaiser, A. P., Spiro, A. III, King, D. W., \& King, L. A. (2012). Does wartime captivity affect late-life mental health? A study of Vietnam-era repatriated prisoners of war. Research in Human Development, 9, 191-209. doi:10.1080/15427609. 2012.705554

Pavalko, E. K., \& Elder, G. H., Jr. (1990). World War II and divorce: A life-course perspective. American Journal of Sociology, 95, 1213. doi:10.1086/229427

Radloff, L. S. (1977). The CES-D Scale: A self-report depression scale for research in the general population. Applied Psychological Measurement, 1, 385-401. doi:10.1177/014662167700100306

RAND HRS Data, Version N. (2012). Produced by the RAND Center for the Study of Aging, with funding from the National Institute on Aging and the Social Security Administration: Santa Monica, CA.

Sampson, R. J., \& Laub, J. H. (1996). Socioeconomic achievement in the life course of disadvantaged men: Military service as a turning point, Circa 1940-1965. American Sociological Review, 61, 347. doi:10.2307/2096353

Schnurr, P. P., Spiro, A. III, \& Paris, A. H. (2000). Physiciandiagnosed medical disorders in relation to PTSD symptoms in older male military veterans. Health Psychology, 19, 91-97. doi:10.1037/0278-6133.19.1.91 
Settersten, R. A. (2006). When nations call: How wartime military service matters for the life course and aging. Research on Aging, 28, 12-36. doi:10.1177/0164027505281577

Settersten, R. A., Jr., \& Patterson, R. S. (2006). Military service, the life course, and aging: An introduction. Research on Aging, 28, 5-11. doi:10.1177/0164027505281579.

Sorrell, J. M., \& Durham, S. (2011). Meeting the mental health needs of the aging veteran population. Journal of Psychosocial Nursing and Mental Health Services, 49, 22-25. doi:10.3928/02793695-20101207-01

Spiro, A., Schnurr, P. P., \& Aldwin, C. M. (1994). Combat-related posttraumatic stress disorder symptoms in older men. Psychology and Aging, 9, 17-26. doi:10.1037/0882-7974.9.1.17

Spiro, A. III, Settersten, R. A., \& Aldwin, C. M. (2016). Long-term outcomes of military service in aging and the life course: A positive re-envisioning. The Gerontologist, 56, 5-13. doi:10.1093/ geront/gnv093

Steffick, D. E. (2000). Documentation of affective functioning measures in the Health and Retirement Study. Ann Arbor, MI: HRS Health Working Group. doi:10.7826/ isr-um.06.585031.001.05.0005.2000

Taylor, M. G., \& Lynch, S. M. (2004). Trajectories of impairment, social support, and depressive symptoms in later life. The Journals of Gerontology, Series B: Psychological Sciences and Social Sciences, 59, 238-246. doi:10.1093/geronb/59.4.s238

Taylor, M. G., Ureña, S., \& Kail, B. L. (2016). Service-related exposures and physical health trajectories among aging veteran men. The Gerontologist, 56, 92-103. doi:10.1093/geront/gnv662

Teachman, J. D. (2013). Setting an agenda for future research on military service and the life course. In J. M. Wilmoth \& A. S.
London (Eds.), Life course perspectives on military service (pp. 255-274). New York, NY: Routledge.

United States Census Bureau. (2010). How do we know? A snapshot of our nation's veterans. Retrieved from http://www.census.gov/ content/dam/Census/library/infographics/veterans.pdf

United States Code of Federal Regulations. (2016). Title 38: Pensions, bonuses, and veterans' relief, $\$ 3.2$, periods of war. Retrieved from http://www.ecfr.gov/cgi-bin/text-idx?SID=814e01f0b34307c6577 $8465 \mathrm{fb} 7 \mathrm{c} 6 \mathrm{e} 420 \& \mathrm{mc}=$ true $\&$ node $=\mathrm{se} 38.1 .3 \_12 \& \operatorname{rgn}=\operatorname{div} 8$

Veterans Health Administration. (2015). One in ten older vets is depressed. Retrieved from http://www.va.gov/health/ NewsFeatures/20110624a.asp

Wilmoth, J. M., London, A. S., \& Parker, W. M. (2010). Military service and men's health trajectories in later life. The Journals of Gerontology, Series B: Psychological Sciences and Social Sciences, 65, 744-755. doi:10.1093/geronb/gbq072

Wilmoth, J. M., \& London, A. S. (2013). Life course perspectives on military service: An Introduction. In J. M. Wilmoth \& A. S. London (Eds.), Life course perspectives on military service (pp. 1-18). New York, NY: Routledge.

Wolf, D. A., Wing, C., \& Lopoo, L. M. (2013). Methodological problems in determining the consequences of military service. In J. M. Wilmoth \& A.S. London (Eds.), Life course perspectives on military service (pp. 255-274). New York, NY: Routledge.

Zivin, K., Pirraglia, P. A., McCammon, R. J., Langa, K. M., \& Vijan, S. (2013). Trends in depressive symptom burden among older adults in the United States from 1998 to 2008. Journal of General Internal Medicine, 28, 1611-1619. doi:10.1007/ s11606-013-2533-y 